\title{
Activation of Carbide Derived Carbons: A Route to Materials with Enhanced Gas and Energy Storage Properties
}

\author{
M. Sevilla ${ }^{\mathrm{a}, \mathrm{b}}$, R. Mokaya*a

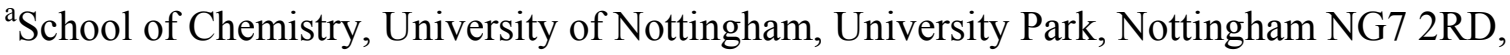 \\ U. K. \\ ${ }^{b}$ Instituto Nacional del Carbón (CSIC), P.O. Box 73, 33080 Oviedo, Spain
}

\begin{abstract}
Thermal halogenation of a wide range of metal carbides provides a simple route to a class of so called carbide derived carbon (CDC) materials. The porosity of the CDCs, which is mainly in the microporous regime, may be modulated by choice of metal carbide precursor and halogenation temperature. However, although the pore size of CDCs can be fine-tuned by the choice of synthesis process, the maximum surface area achieved is only up to $2500 \mathrm{~m}^{2} \cdot \mathrm{g}^{-1}$, which limits their use in gas storage or in electrochemical capacitor applications that require larger surface areas. The article is focussed on what has and can be done to enhance the textural properties of CDCs via further post-synthesis treatments and the ramifications of such modifications on their gas/energy storage capacity. The main developments in physical and chemical activation of CDCs and consequences on gas and energy storage are summarised.
\end{abstract}




\section{Introduction}

The best way of getting the maximum performance from a material is to design it so that it has properties that perfectly fit the requirements of the targeted application. In this sense, the careful control and tuning of the porous structure of carbon materials is required for various applications, such as gas (e.g., hydrogen) storage or in electrochemical capacitors. Thus, several studies have shown the influence of pore size on the hydrogen storage capacity of carbon materials, and in particular the crucial role of narrow micropores (see Figure 1a), which are more efficient for hydrogen uptake due to a stronger interaction between the pore walls and the hydrogen molecules. ${ }^{1-5}$ Similarly, studies have shown that the highest capacitance in an electrochemical capacitor is achieved when the size of pores in the carbon material matches that of the electrolyte ions, ${ }^{6-10}$ as illustrated in Figure 1b. This has been attributed to distortion and partial desolvation of ions minimizing the distance between the ion and the pore wall. ${ }^{6,9}$ However, for high power applications the presence of larger pores might be beneficial. ${ }^{6,10}$ For gas storage and electrochemical capacitor applications, the carbons should possess large surface areas accessible to the sorbate (for sorption processes) or electrolyte (for electrochemical capacitors) as these processes depend on surface area.

Carbon materials with a narrow pore size distribution centred in the micropore range can be obtained by two methods: i) a nanocasting technique using zeolite as template to generate the so-called zeolite-templated carbons (ZTCs), and ii) selective thermochemical etching, by high-temperature chlorination, melts, supercritical water or vacuum deposition, of the metal from a rigid metal carbide lattice (e.g., $\mathrm{ZrC}, \mathrm{TiC}, \mathrm{SiC}$ ) to generate carbide derived carbons (CDCs).

The template based nanocasting technique is a multi-step technique which basically consists of the carbonization of an organic compound in the nanospace of an inorganic 
substance which acts as template and the liberation of the resultant carbon from the template (Figure 2a). As a result, a carbon material is formed whose porosity is an inverse replica of the template inorganic framework. This technique allows the formation of carbon materials with relatively well controlled structural characteristics (i.e., surface area, pore volume, pore size, particle size, morphology, etc.) by selecting the appropriate zeolite template and nanocasting conditions. However, given that zeolites are highly crystalline aluminosilicate materials that possess uniform subnanometre sized pore and pore walls that are determined by a lattice structure, it is difficult to fine tune the pore size of ZTCs. The synthesis of CDCs, on the other hand, consists of heat treatment of metallic carbides under inert atmosphere followed by chlorination at an elevated temperature. This process may also be considered to be a nanocasting method, as the rigid metal carbide lattice acts as template, with the metal atoms extracted layer-by-layer, so that the final carbon structure is 'templated' by the carbide structure (see Figure $2 \mathrm{~b}$ ). In this case, there is the possibility of tuning the porosity at the atomic level (i.e., with subångström accuracy) in a wide range by controlling the chlorination temperature or by selection of precursor carbide (composition, lattice type). ${ }^{12,13}$ Although the pore size of CDCs can be fine-tuned by the choice of synthesis process, the final carbon materials only achieve a maximum surface area of $2000-2500 \mathrm{~m}^{2} \cdot \mathrm{g}^{-1}$. This is a limitation because their use in gas storage or in electrochemical capacitor applications requires larger surface areas. This is especially the case for gas storage or energy for mobile applications. The scope of this progress report is focussed on what has and can be done to enhance the textural properties of CDCs via further post-synthesis treatments and the ramifications of such modifications on their gas/energy storage capacity. 


\section{Synthesis and Porosity Control of Carbide-derived Carbons by Thermal}

\section{Halogenation}

Chlorination of metallic carbides has been traditionally used for the production of metal tetrachlorides. Thus, in 1918, Hutchins patented a method for the production of silicon tetrachloride by reaction of silicon carbide with chlorine gas according to: $\mathrm{SiC}+2 \mathrm{Cl}_{2}=$ $\mathrm{SiCl}_{4}+\mathrm{C} .{ }^{14}$ The main product of the reaction was silicon tetrachloride vapour, whereas the residual carbon, considered to be in the form of graphite, was disposed. However, it was not until 1959 that this carbon residue attracted the attention of researchers, and Mohun ${ }^{15}$ introduced the carbide-derived carbons as a "fourth class of amorphous carbon". The most commonly used etching agent is $\mathrm{Cl}_{2}$ but other halogens such as $\mathrm{Br}_{2}$, $\mathrm{F}_{2}$ and $\mathrm{I}_{2}$ or their compounds such as $\mathrm{HF}, \mathrm{CCl}_{4}, \mathrm{CHCl}_{3}$ etc. can be used instead of $\mathrm{Cl}_{2}{ }^{16}$ The general reaction involved in the synthesis of carbon from metal carbides can be written as:

$$
\mathrm{Me}_{\mathrm{x}} \mathrm{C}_{\mathrm{y}(\mathrm{s})}+(\mathrm{z} / 2) \mathrm{Cl}_{2(\mathrm{~g})} \rightarrow \mathrm{x} \mathrm{MeCl}_{\mathrm{z}(\mathrm{g})}+\mathrm{y} \mathrm{C}_{(\mathrm{s})}
$$

where Me represents metal.

This method has the following advantages: i) it is versatile as it can be used to obtain carbon from a variety of metal carbides, since most of the metals form volatile halides, ii) it is a low-cost process as many of the precursor carbides are inexpensive, iii) as metal is extracted layer-by-layer from the rigid metal carbide lattice, there is the possibility of controlling the porosity at the atomic level, ${ }^{11}$ iv) as pore formation is due to removal of metal in the form of gaseous metal chloride, CDCs contain open pores and v) the transformation of metal carbide to carbon is conformal and does not lead to changes in the sample size and shape.

The porous structure of CDCs was first investigated by Boehm and Warnecke in 1975, when they showed that carbons obtained from TaC possess a microporous 
structure. ${ }^{17}$ Since then, the number of articles dealing not only with the synthesis of CDCs, but also with the tailoring of their textural characteristics has increased considerably. ${ }^{12,13,18-35}$ Early studies established that CDCs could be successfully synthesised from a great variety of metal carbides including $\mathrm{ZrC}, \mathrm{SiC}, \mathrm{TiC}, \mathrm{Mo}_{2} \mathrm{C}$ and $\mathrm{B}_{4} \mathrm{C},{ }^{21-26}$ and showed that, depending on the type of carbide used, pore sizes in the $0.8-$ $2 \mathrm{~nm}$ range can be achieved. Latter reports, by Gogotsi and co-workers, have focussed on the control of the pore size of CDCs by varying the chlorination temperature for any given carbide. ${ }^{12,18,20,21,27-32}$ Thus, Gogotsi and co-workers have demonstrated the possibility of tuning the pore size of CDCs, with subångström accuracy, by modifying the chlorination temperature between 300 and $1200^{\circ} \mathrm{C}$ for $\mathrm{Ti}_{3} \mathrm{SiC}_{2}(0.5-0.8 \mathrm{~nm}),{ }^{12}$ in the $600-1200^{\circ} \mathrm{C}$ range for $\mathrm{B}_{4} \mathrm{C}(0.66->2 \mathrm{~nm}),{ }^{27}$ in the $300-1200^{\circ} \mathrm{C}$ range for $\mathrm{ZrC}$ $(0.76-1.41 \mathrm{~nm})^{28}$ and $400-800^{\circ} \mathrm{C}$ for $\mathrm{Mo}_{2} \mathrm{C}(1.26-3.2 \mathrm{~nm}) .{ }^{29}$ Likewise, Urbonaite and co-workers tuned the pore size in the $0.8-2.7 \mathrm{~nm}$ range for a variety of metal carbides (VC, TiC, $\mathrm{WC}, \mathrm{TaC}, \mathrm{NbC}, \mathrm{HfC}$ and $\mathrm{ZrC}$ ) by chlorinating at $700-1200^{\circ} \mathrm{C} .^{18}$ Similarly, Jänes and co-workers controlled the pore size of VC in the $1.17-2.15 \mathrm{~nm}$ range by modifying the chlorination temperature between $500-1100^{\circ} \mathrm{C}^{32,33}$ and between 0.8 and $4 \mathrm{~nm}$ for $\mathrm{Mo}_{2} \mathrm{C}$ by increasing the temperature from 400 to $1200^{\circ} \mathrm{C} .^{34}$ More recently, Leis and co-workers modified the pore size distribution of CDCs obtained from $\mathrm{Mo}_{2} \mathrm{C}$ by varying the chlorination temperature in the $500-900^{\circ} \mathrm{C}$. Thus, the average pore size of the carbons was increased from 1 to $2 \mathrm{~nm}$ with the increase of the chlorination temperature. ${ }^{35}$ In all studies, the surface area and pore volume of the CDCs were between 200 and $2500 \mathrm{~m}^{2} \cdot \mathrm{g}^{-1}$ and 0.18 and $1.68 \mathrm{~cm}^{3} \cdot \mathrm{g}^{1}$ respectively as shown in Table 1. The pore size increase and broadening of pore size distribution at higher chlorination temperature is due to the greater diffusion rate of carbon atoms, which allows them to arrange themselves in more ordered carbon structures leading to 
the formation of multi-layer graphitic structures (as shown by the TEM image in Figure 3a), which in turn encourages the formation of larger pores. On the other hand, for low chlorination temperatures, the diffusion of carbon atoms is slow and they are only slightly displaced from their original positions in the metal carbide lattice, so that the morphology of the carbon network formed is close to the distribution of carbon atoms in the initial carbide structure (Figure 3b). ${ }^{28}$ More recently, Rose and co-workers have reported on the synthesis of CDC fibres exhibiting high surface areas, up to 3116 $\mathrm{m}^{2} \cdot \mathrm{g}^{-1},{ }^{36}$ value higher than those normally reported for CDCs (see Table 1 ). The procedure comprises three steps: i) electrospinning of solutions of polycarbomethylsilane (PCS) in tetrahydrofurane, ii) pyrolisis of the resulting fibre and finally, iii) chlorination. However, these CDCs are characterized by broader PSDs (which extend in the micro and mesopore range, up to $2.5 \mathrm{~nm}$ ) than those obtained by chlorination of crystalline $\mathrm{SiC}$, which exhibit a narrow PSD below $2 \mathrm{~nm}$.

Due to their finely-tunable porosity and high surface area, CDCs are promising candidates for gas (hydrogen, methane) and energy (electrochemical capacitor) storage. In fact, the controlled pore size distribution of CDCs has allowed the study of the influence of the pore size on the gas and energy storage capacity of porous carbon materials. Thus, it has been found that the optimum pore size for hydrogen and methane storage is $0.6-0.65 \mathrm{~nm}$ and $1.1 \mathrm{~nm}$ respectively, whereas for energy storage it is $0.7-$ $1.0 \mathrm{~nm}$ (see Figure 1). The optimum pore size has been determined not only experimentally, ${ }^{1,2,6,8-10,37}$ but has also been corroborated theoretically. ${ }^{3,38-41}$ Nevertheless, in spite of this qualitative determinations, CDCs exhibit low to moderate values of hydrogen storage capacity in the $2.9-4.4 \mathrm{wt} \%$ range (measured at $-196^{\circ} \mathrm{C}$ and 60 bar $)^{4,13,42}$ and methane storage capacity in the $9-16 \mathrm{wt} \%(80-140 \mathrm{v}(\mathrm{STP}) / \mathrm{v})$ range (measured at $25^{\circ} \mathrm{C}$ and 60 bar). ${ }^{18,41}$ This gas storage values are below the hydrogen 
storage target of $6 \mathrm{wt} \%$ (at a workable temperature and pressure) set by the US Department of Energy (DOE) for an on-board hydrogen storage system to be achieved by $2010,{ }^{43}$ and $180 \mathrm{v}(\mathrm{STP}) / \mathrm{v}$ (standard temperature and pressure equivalent volume of methane per volume of the adsorbent materials) at 35 bar and ambient temperature. ${ }^{44}$ The below target gas storage capacity is due to the following reasons: i) CDCs with high surface areas and pore volume tend to have larger pore sizes $(>2 \mathrm{~nm})$, which are less efficient for gas storage, and ii) the highest surface area reported for a CDC is limited to ca. $2500 \mathrm{~m}^{2} \cdot \mathrm{g}^{-1}$ (with pore size of $2.6 \mathrm{~nm}$ ), ${ }^{29}$ a value not high enough for storing large amounts of gas, and lower than that obtained for activated carbons. One exception is the CDCs fibres above described, which can exhibit a surface area up to $3116 \mathrm{~m}^{2} \cdot \mathrm{g}^{-1}$. However, these fibres only adsorbed $3.86 \mathrm{wt} \%$ at 17 bar and $77 \mathrm{~K}$, due probably to their broad PSD, which extends into the mesopore region. With regards to energy storage, Chmiola and co-workers, taking advantage of the narrow and tunable PSD of the CDCs, showed an anomalous increase in carbon capacitance at pore sizes less than $1 \mathrm{~nm}$ (see Figure 1b). ${ }^{6}$ Thus, defying traditional beliefs about inaccessibility of small pores to solvated ions and thus no contribution of these pores to energy storage, they demonstrated that these tailored sub-nanoporous materials exhibit very high capacitance in an acetonitrile-based organic electrolyte. These results were explained by a desolvation of the electrolyte ions entering sub-nanometer pores, the distance between the ion and the carbon surface being reduced, which results in an increase of the capacitance. In this way, the specific capacitance of CDCs is in the $150-250 \mathrm{~F} \cdot \mathrm{g}^{-1} \mathrm{range}$ in aqueous electrolyte, ${ }^{10,45,46}$ and $100-170 \mathrm{~F} \cdot \mathrm{g}^{-1}$ in organic electrolyte. ${ }^{9,46-49}$ Lately, the use of ion liquids as electrolytes in supercapacitors is increasing due to their wider voltage operating window and thus the amount of energy storage higher. Additionally, they are solvent-free, relatively cheap, highly conductive and thermal stable and 
environment friendly. In this case, the capacitance values of the CDCs are 100-160 $\mathrm{F} \cdot \mathrm{g}^{-1}$, the maximum capacitance being achieved when the pore size is in the range of the ion size. ${ }^{50,51}$ Therefore, despite exhibiting certain attractive features, CDCs have only been able to achieve a maximum surface area that is lower than that of activated carbons and ZTCs. This significantly limits their gas and energy storage capacity. These limitations have recently spurred the development of processes that increase both the surface area and microporosity of CDCs.

\section{Enhancement of Porosity and Energy Storage Capacity of CDCs via Post- Synthesis Activation}

The post-synthesis activation of CDCs (via both physical and chemical methods) has recently been explored as a way of increasing their efficiency in gas or energy storage. Although carbon activation is a well-known and established process for enhancing the porous characteristics of carbonaceous materials, the potential benefits of the postsynthesis activation of CDCs are only just beginning to become evident. Thus, reports on the physical or chemical activation of CDCs and the influence of such treatment on their gas or energy storage are just starting to be published. Gogotsi and co-workers have studied the physical (with air and carbon dioxide) and chemical (with $\mathrm{KOH}$ ) activation of $\mathrm{CDCs}$ synthesized from $\mathrm{TiC}$ at different temperatures $\left(400-1000^{\circ} \mathrm{C}\right)$ and the influence of the activation on hydrogen storage capacity, ${ }^{4,52}$ and methane storage capacity. ${ }^{53}$ These early studies on post-synthesis activation of CDCs demonstrated the possibility of enhancing and adjusting the porosity of CDCs through the use of chemical or physical activation, and the importance of the activation temperature and duration. Short periods of activation lead to an increase in the micropore volume, whereas high activation temperatures and longer treatment durations favour the formation of mesopores. On activation, surface area and pore volume up to $3360 \mathrm{~m}^{2} \cdot \mathrm{g}^{-1}$ and $\sim 1.4$ 
$\mathrm{cm}^{3} \cdot \mathrm{g}^{-1}$ respectively were achieved, which are double that of the raw $\mathrm{CDC}$. The higher total pore volume is however, accompanied by a decrease of the micropore volume and the appearance of an additional mesopore volume contribution. Thus, whereas the raw CDCs are characterized by an average pore size of $0.65-1.1 \mathrm{~nm}, \mathrm{KOH}$ activated CDCs possess an average pore size of $1.17-1.3 \mathrm{~nm}$, while $\mathrm{CO}_{2}$ activated $\mathrm{CDCs}$ have pore size of $0.8-1.88 \mathrm{~nm}$ (Table 2). Moreover, whereas in the raw CDCs there are no pores larger than $1.7 \mathrm{~nm}$, in the activated CDCs there are pores of size up to $4 \mathrm{~nm}$. The development of mesoporosity is, in principle, undesirable with respect to hydrogen storage, where an optimum pore size of $0.60-0.65 \mathrm{~nm}$ is required. Nevertheless, Gogotsi and co-workers found an enhancement in hydrogen uptake (at $-196^{\circ} \mathrm{C}$ and 60 bar) of up to $52 \%$ compared to the raw CDCs, reaching a value of $4.7 \mathrm{wt} \%$, which however still remains far from the DOE's target. This increase in hydrogen uptake is attributed to the higher surface area, which compensates for the decreased micropore volume contribution. These results show therefore that the optimal CDC activation conditions for maximizing hydrogen storage capacity are a compromise between high surface area and total pore volume versus the micropore volume. On the other hand, as previously stated, the optimum pore size for methane storage is $1.1 \mathrm{~nm}$, and therefore, the higher porosity achieved through activation of CDCs is beneficial for methane uptake. Indeed, Gogotsi and co-workers observed an enhancement of $30-50 \%$ in methane uptake of activated CDCs compared to raw CDCs as shown in Figure 4.

We have recently studied the influence of chemical activation on the porosity and hydrogen storage capacity of CDCs derived from zirconium carbide. ${ }^{54}$ Although chemical activation of the $\mathrm{Zr}$-CDC caused a broadening of the pore size distribution (Figure 5a), the resulting superactivated CDCs were still remarkably highly microporous, with typically $90 \%$ of surface area and $80 \%$ of pore volume associated 
with micropores. As a result, the observed porosity increase (i.e., 47 and 58\% increase in the surface area and pore volume respectively) was accompanied by an enhancement of up to $63 \%$ in hydrogen uptake capacity (Figure $5 b$ ). The supercativated CDC with the highest surface area and pore volume achieved values of $2770 \mathrm{~m}^{2} \cdot \mathrm{g}^{-1}$ and $1.47 \mathrm{~cm}^{3} \cdot \mathrm{g}^{-1}$ respectively, which translated into an improved hydrogen uptake capacity of $6.2 \mathrm{wt} \%$ at $-196^{\circ} \mathrm{C}$ and 20 bar. Moreover, at 1 bar the superactivated CDCs store up to $2.7 \mathrm{wt} \%$ hydrogen, which is amongst the highest values ever reported for activated carbon.

With regards to energy storage in electrochemical capacitors, Gogotsi and coworkers have obtained results that mirror those for hydrogen storage for Ti-CDC chemically activated with $\mathrm{KOH} .{ }^{55}$ That is, although subnanometre pores are best suited for improving the capacitance, the overall increase in surface area and volume of pores between 1 and $2 \mathrm{~nm}$ compensates for the decrease in subnanometre pore volume in the activated $\mathrm{CDC} .^{55}$ Thus, gravimetric capacitance was enhanced by $30 \%$ when the surface area and volume from pores of size larger than the solvated ion size increased, achieving a value of $180 \mathrm{~F} / \mathrm{g}$ in organic electrolyte. This value is much higher than that observed for other activated carbons in the same organic electrolyte. ${ }^{56,57}$

\section{Conclusions and Future Outlook}

The results highlighted above show that activation of CDCs is a powerful tool for improving the performance of the CDCs in gas or energy storage. CDCs are a special class of porous carbons that are readily obtained from a wide range of metal carbides via thermal halogenation and whose porosity can be finely tuned by simple changes in their preparation. Although activation of CDCs has only recently been reported, it has already been demonstrated that both physical and chemical activation routes can be used to further improve and fine-tune the porosity of CDCs in a manner not possible for other forms of activated carbons. In general, where carefully done, the activation of CDCs 
offers significant (typically $50-60 \%$ ) improvements with respect to their application in gas and energy storage. However, as illustrated for hydrogen storage applications, where small micropores of size ca. $0.7 \mathrm{~nm}$ are required, the activation of CDCs should be performed with care so as to avoid undesirable porosity changes (e.g., the excessive formation of mesoporosity). Further work with a greater variety of activating agents, and better balance between preparation (i.e., thermal halogenation) and activating conditions should in future generate very high surface area carbon materials with optimised microporosity or small mesopore porosity for targeted applications.

\section{Acknowledgement}

M. S. acknowledges the assistance of the Spanish MICINN for the award of a postdoctoral mobility contract.

\section{References}

1. M. G. Nijkamp, J. E. M. J. Raaymakers, A. J. van Dillen and K. P. de Jong, Appl. Phys. A, 2001, 72, 619-623.

2. R. Ströbel, J. Garche, P. T. Moseley, L. Jörissen and G. Wolf, J. Power Sources, 2006, 159, 781-801.

3. I. Cabria, M. J. López and J. A. Alonso, Carbon, 2007, 45, 2649-2658.

4. Y. Gogotsi, C. Portet, S. Osswald, J. M. Simmons, T. Yildirim, G. Laudisio and J. E. Fischer, Int. J. Hydrogen Energy., 2009, 34, 6314.

5. G. Yushin, R. Dash, J. Jagiello, J.E. Fischer and Y. Gogotsi, Adv. Funct. Mater., 2006, 16, 2288-2293.

6. J. Chmiola, G. Yushin, Y. Gogotsi, C Portet,. P. Simon and P. L. Taberna, Science, 313, 1760-63, 2006.

7. A. Janes and E. Lust, J. Electrochem. Soc., 2006, 153, A113-A116. 
8. E. Raymundo-Piñero, K. Kierzek, J. Machnikowski and F. Beguin, Carbon, 2006, 44, 2498-2507.

9. J. Chmiola, C. Largeot, P-L Taberna, P. Simon and Y. Gogotsi, Angew. Chem. Int. Ed., 2008, 47, 3392-3395.

10. J. Chmiola, G. Yushin, R. Dash and Y. Gogotsi, J. Power Sources, 2006, 158, $765-$ 772.

11. H. Nishihara, Q. H. Yang, P. X. Hou, M. Unno, S. Yamauchi, R. Saito, J. I. Paredes, A. Martinez-Alonso, J. M. D. Tascon, Y. Sato, M. Terauchi and T. Kyotani, Carbon, 2009, 47, 1220-1230.

12. Y. Gogotsi, A. Nikitin, H. Ye, W. Zhou, J. E. Fischer, B. Yi, H. C. Foley and M. W. Barsoum, Nature Mater., 2003, 2, 591-594.

13. Y. Gogotsi, R. K. Dash, G. Yushin, T. Yildirim, G. Laudisio and J. E Fischer, J. Am. Chem. Soc., 2005, 127, 16006-16007.

14. O. Hutchins, U.S. Patent 1, 271, 713, 1918.

15. W. A. Mohun, in "Proc. 4th Biennial Conf. Carbon," p. 443. Pergamon, Oxford, 1959.

16. G. Yushin, Y. Gogotsi and A. Nikitin, in Nanomaterials Handbook, Ed. Y. Gogotsi, CRC Press, Boca Raton, FL 2005, Ch. 8, p. 237-280.

17. H. P. Boehm and H. H. Warnecke, in Proc. 12th Biennial Conf. on Carbon 149-150 (Pergamon, Oxford, 1975).

18. S. Urbonaite, J.M. Juárez-Galán, J. Leis, F. Rodríguez-Reinoso and G. Svensson, Microporous Mesoporous Mater., 2008, 113, 14-21.

19. R. Dash, J. Chmiola, G. Yushin, Y. Gogotsi, L. Giovanna, J. Singer, J. E. Fischer and S. Kucheyev, Carbon, 2006, 44, 2489.

20. Y. Gogotsi, J. D. Jeon and M. J. McNallan, J. Mater. Chem., 1997, 7, 1841-1848. 
21. N. F. Fedorov, Ross. Khim. Zh., 1995, 39, 37.

22. N. F. Fedorov, G. K. Shikhnyuk and D. N. Gavrilov, Zh. Prikl. Khim., (Leningrad) 1982, 54, 272.

23. S. K. Gordeev and A. V. Vartanova, Zh. Prikl. Khim., (St. Petersburg) 1995, 67, 1080.

24. A. E. Kravchik, A. S. Osmakov and R. G. Avarbé, Zh. Prikl. Khim., (Leningrad) 1989, 61, 2430.

25. R. N. Kyutt, É. A. Smorgonskaya, S. K. Gordeev, A. M. Danishevskiı̌, S. K. Gordeev and A. V. Grechinskaya, Phys. Solid State, 1999, 41, 1359-1363.

26. R. K. Dash, A. Nikitin and Y. Gogotsi, Microporous Mesoporous Mater., 2004, 72 , 203-208.

27. R. K. Dash, G. Yushin and Y. Gogotsi, Microporous Mesoporous Mater., 2005, 86, $50-57$.

28. H. S. Kim, J. P. Singer, Y. Gogotsi and J. E. Fischer, Microporous Mesoporous Mater., 2009, 120, 267-271.

29. M. Kormann, H. Gerhard and N. Popovska, Carbon, 2009, 47, 242-250.

30. S-H. Yeon. P. Reddington, Y. Gogotsi, J. E. Fischer, C. Vakifahmetoglu and P. Colombo, Carbon, 2010, 48, 201-210.

31. A. Jänes, T. Thomberg and E. Lust, Carbon, 2007, 45, 2717-2722.

32. A. Jänes, T. Thomberg and E. Lust, Carbon, 2007, 45, 2717-2722.

33. A. Jänes, T. Thomberg, H. Kurig and E. Lust, J. Electroanal. Chem., 2009, 630, 5562.

34. J. Leis, M. Arulepp, M. Käärik, A. Perkson. Carbon, 2010, 48, 4001-4008.

35. M. Rose, E. Kockrick, I. Senkovska and S. Kaskel, Carbon, 2010, 48, 403-407. 
36. J-W. Lee, M. S. Balathanigaimani, H-C. Kang, W-G. Shim, C. Kim and H. Moon, J. Chem. Eng. Data, 2007, 52, 66-70.

37. M. Rzepka, P. Lamp and M. A. de la Casa-Lillo, J. Phys. Chem. B, 1998, 102, 10894-10898.

38. I. Cabria, M. J. López and J. A. Alonso, Phys. Rev. B, 2008, 78, 075415, 9 pp.

39. J. Sun, T. D. Jarvi, L.F. Conopask and S. Satyapal, Energy Fuels, 2001, 15, 1241 1246.

40. J. Huang, B. G. Sumpter and C. Meunier, Chem. Eur. J., 2008, 14, 6614-6626.

41. S.-H. Yeon, I. Knoke, Y. Gogotsi and J. E. Fischer, Microporous Mesoporous Mater., 2010, 131, 423-428.

42. DOE Hydrogen Program, FY 2004 Progress Report.

$<$ http://www.eere.energy.gov/hydrogenandfuelcells/pdfs/annual04/iii_storage_intro.pdf >. 179-181 (2004).

43. S. Ma, D. Sun, J. M. Simmons, C. D. Collier, D. Yuan and H.-C. Zhou, J. Am. Chem. Soc. 2008, 130, 1012-1016.

44. A. Nikitin and Y. Gogotsi, Nanostructured carbide-derived carbons in Encyclopedia of Nanoscience and Nanotechnology. Edited by H.S. Nalwa. Volume 10, Pages 1-22, 2004.

45. J. A. Fernández, M. Arulepp, J. Leis, F. Stoeckli and T. A. Centeno, Electrochim. Acta, 2080, 53, 7111-7116.

46. Y. Korenbit, M. Rose, E. Kockrick, L. Borchardt, A. Kvit, S. Kaskel and G. Yushin, ACS Nano, 2010, 4, 1337-1344.

47. T. Thomberg, A. Jänes and E. Lust, Electrochim. Acta, 2010, 55, 3138-3143.

48. A. Jänes, L. Permann, M. Arulepp and E. Lust, Electrochem. Commun., 2004, 6, 313-318. 
49. C. Largeot, C. Portet, J. Chmiola, P-L. Taberna, Y. Gogotsi and P. Simon, J. Am. Chem. Soc., 2008, 130, 2730-2731.

50. H. Kurig, A. Jänes and E. Lust, J. Electrochem. Soc., 2010, 157, A272-A279.

51. S. Osswald, C. Portet, Y. Gogotsi, G. Laudisio, J. P. Singer, J. E. Fischer, V. V. Sokolov, J. A. Kukushkina and A. E. Kraychik, J. Solid State Chem., 2009, 182, 1733. 52. S-H. Yeon, S. Osswald, Y. Gogotsi, J. P. Singer, J. M. Simmons, J. E. Fischer, M. A. Lillo-Ródenas and A. Linares-Solano, J. Power Sources, 2009, 191, 560-567.

53. M. Sevilla, R. Foulston and R. Mokaya, Energy Environ. Sci., 2010, 3, 223-227.

54. C. Portet, M. A. Lillo-Ródenas, A. Linares-Solano and Y. Gogotsi, Phys. Chem. Chem. Phys., 2009, 11, 4943-4945.

55. J. Gamby, Taberna, P. L. Simon, P. Fauvarque, J. F. Chesneau, M. J. Power Sources, 2001, 101, 109-116.

56. G. Lota, T. A. Centeno, E. Frackowiac and F. Stoeckli, Electrochim. Acta, 2008, 53, $2210-2216$. 
Table 1. Porous characteristics of various carbide-derived carbons.

\begin{tabular}{|c|c|c|c|c|c|c|}
\hline Precursor & $\mathrm{T}\left({ }^{\mathrm{a}} \mathrm{C}\right)$ & $\begin{array}{c}\text { Surface area } \\
{\left[\mathrm{m}^{2} \mathrm{~g}^{-1}\right]}\end{array}$ & $\begin{array}{l}\text { Pore volume } \\
\qquad\left[\mathrm{cm}^{3} \mathrm{~g}^{-1}\right]\end{array}$ & $\begin{array}{l}V_{\text {micropore }} \\
{\left[\mathrm{cm}^{3} \mathrm{~g}^{-1}\right]}\end{array}$ & $\begin{array}{c}\text { Average pore } \\
\text { size } \\
{[\mathrm{nm}]}\end{array}$ & Ref. \\
\hline \multirow[t]{4}{*}{$\mathrm{Ti}_{3} \mathrm{SiC}_{2}$} & 300 & - & - & - & $0.51^{\mathrm{d}}$ & \multirow{4}{*}{12} \\
\hline & 500 & - & - & - & $0.58^{\mathrm{d}}$ & \\
\hline & 800 & - & $\sim 0.64$ & - & $0.78^{d}$ & \\
\hline & 1100 & - & $\sim 0.64$ & - & $0.76^{\mathrm{d}}$ & \\
\hline \multirow[t]{4}{*}{$\mathrm{ZrC}$} & 300 & $\sim 500$ & $\sim 0.20$ & $\sim 0.20^{\mathrm{a}}$ & $0.76^{\mathrm{e}}$ & \multirow{4}{*}{28} \\
\hline & 600 & $\sim 900$ & $\sim 0.50$ & $\sim 0.45^{\mathrm{a}}$ & $0.80^{\mathrm{e}}$ & \\
\hline & 800 & $\sim 1350$ & $\sim 0.62$ & $\sim 0.5^{\mathrm{a}}$ & $0.83^{\mathrm{e}}$ & \\
\hline & 1200 & $\sim 1900$ & 0.95 & $\sim 0.46^{\mathrm{a}}$ & $1.41^{\mathrm{e}}$ & \\
\hline \multirow[t]{4}{*}{$\mathrm{Mo}_{2} \mathrm{C}$} & 400 & 1093 & 0.55 & $\sim 0.30^{\mathrm{b}}$ & $1.26^{\mathrm{e}}$ & \multirow{4}{*}{29} \\
\hline & 600 & $\sim 2240$ & 1.18 & $\sim 0.35^{\mathrm{b}}$ & $1.8^{\mathrm{e}}$ & \\
\hline & 700 & 2520 & 1.59 & $\sim 0.40^{\mathrm{b}}$ & $2.6^{\mathrm{e}}$ & \\
\hline & 800 & 2128 & 1.68 & $\sim 0.27^{b}$ & $3.2^{\mathrm{e}}$ & \\
\hline \multirow[t]{3}{*}{$\mathrm{TiC}$} & 700 & 1265 & - & $0.50^{\mathrm{c}}$ & $0.81 / 1.36^{\mathrm{e}}$ & \multirow{15}{*}{18} \\
\hline & 900 & 1599 & - & $0.66^{\mathrm{c}}$ & $0.84 / 1.36^{\mathrm{e}}$ & \\
\hline & 1200 & 1077 & - & $0.65^{\mathrm{c}}$ & $0.87 / 2.74^{\mathrm{e}}$ & \\
\hline \multirow[t]{2}{*}{$\mathrm{VC}$} & 700 & 1683 & - & $0.69^{\mathrm{c}}$ & $0.79 / 1.46^{\mathrm{e}}$ & \\
\hline & 1000 & 1138 & - & $0.53^{c}$ & $0.80 / 2.18^{\mathrm{e}}$ & \\
\hline \multirow[t]{2}{*}{ WC } & 700 & 474 & - & $0.26^{\mathrm{c}}$ & $1.27 / 2.71^{\mathrm{e}}$ & \\
\hline & 1000 & 2036 & - & $1.00^{c}$ & $0.83 / 2.37^{\mathrm{e}}$ & \\
\hline \multirow[t]{2}{*}{$\mathrm{TaC}$} & 700 & 1963 & - & $0.83^{\mathrm{c}}$ & $0.82 / 1.48^{\mathrm{e}}$ & \\
\hline & 1000 & 2275 & - & $1.01^{\mathrm{c}}$ & $0.83 / 2.07^{\mathrm{e}}$ & \\
\hline \multirow[t]{2}{*}{$\mathrm{NbC}$} & 700 & 1864 & - & $0.78^{\mathrm{c}}$ & $0.79 / 1.46^{\mathrm{e}}$ & \\
\hline & 1000 & 1721 & - & $0.78^{\mathrm{c}}$ & $0.84 / 2.17^{\mathrm{e}}$ & \\
\hline \multirow[t]{2}{*}{$\mathrm{HfC}$} & 700 & 1590 & - & $0.69^{c}$ & $0.79 / 1.41^{\mathrm{e}}$ & \\
\hline & 1000 & 1833 & - & $0.82^{c}$ & $0.86 / 2.04^{\mathrm{e}}$ & \\
\hline \multirow[t]{2}{*}{$\mathrm{ZrC}$} & 700 & 1688 & - & $0.68_{c}$ & $0.56 / 1.17^{\mathrm{e}}$ & \\
\hline & 1000 & 1692 & - & $0.74^{\mathrm{c}}$ & $0.79 / 1.98^{\mathrm{e}}$ & \\
\hline \multirow[t]{3}{*}{$\mathrm{VC}$} & 500 & 1163 & 0.51 & $0.47^{\mathrm{a}}$ & $1.17^{\mathrm{e}}$ & \multirow{3}{*}{32,33} \\
\hline & 800 & 1286 & 0.65 & $0.59^{\mathrm{a}}$ & $1.24^{\mathrm{e}}$ & \\
\hline & 1100 & 236 & 0.18 & $0.10^{\mathrm{a}}$ & $2.15^{\mathrm{e}}$ & \\
\hline
\end{tabular}

${ }^{\mathrm{a}}$ Volume of pores $<2 \mathrm{~nm}$ determined via NLDFT. ${ }^{\mathrm{b}}$ Volume of pores $<1.5 \mathrm{~nm}$ determined via NLDFT. ${ }^{\mathrm{c}}$ Determined via $\alpha_{\mathrm{s}}$-plot method. ${ }^{\mathrm{d}}$ Determined via H-K method. ${ }^{\mathrm{e}}$ Determined via NLDFT assuming slit-shaped pores. 
Table 2. Porous characteristics of activated carbide-derived carbons.

\begin{tabular}{|c|c|c|c|c|c|c|c|}
\hline Precursor & $\mathrm{T}\left({ }^{\mathrm{a}} \mathrm{C}\right)$ & $\begin{array}{l}\text { Activation } \\
\text { conditions }\end{array}$ & $\begin{array}{c}\text { Surface area } \\
{\left[\mathrm{m}^{2} \mathrm{~g}^{-1}\right]}\end{array}$ & $\begin{array}{l}\text { Pore volume } \\
{\left[\mathrm{cm}^{3} \mathrm{~g}^{-1}\right]}\end{array}$ & $\begin{array}{l}V_{\text {micropore }} \\
{\left[\mathrm{cm}^{3} \mathrm{~g}^{-1}\right]}\end{array}$ & $\begin{array}{c}\text { Average } \\
\text { pore size } \\
{[\mathrm{nm}]^{\mathrm{a}}}\end{array}$ & Ref. \\
\hline $\mathrm{TiC}$ & $\begin{array}{c}400 \\
500 \\
600 \\
800 \\
1000\end{array}$ & $\begin{array}{c}\mathrm{KOH} / \mathrm{CDC} 3 / 1 \\
\text { (wt./wt.), } 750^{\circ} \mathrm{C}-1 \mathrm{~h} \\
\\
\mathrm{CO}_{2}, 875^{\circ} \mathrm{C}-2 \mathrm{~h} \\
\mathrm{CO}_{2}, 875^{\circ} \mathrm{C}-4 \mathrm{~h} \\
\mathrm{CO}_{2}, 875^{\circ} \mathrm{C}-6 \mathrm{~h} \\
\mathrm{CO}_{2}, 900^{\circ} \mathrm{C}-2 \mathrm{~h} \\
\mathrm{CO}_{2}, 930^{\circ} \mathrm{C}-2 \mathrm{~h} \\
\mathrm{CO}_{2}, 950^{\circ} \mathrm{C}-2 \mathrm{~h} \\
\mathrm{CO}_{2}, 960^{\circ} \mathrm{C}-1 \mathrm{~h}\end{array}$ & $\begin{array}{l}2228 \\
1991 \\
2307 \\
2471 \\
1708 \\
1721 \\
2409 \\
2643 \\
1860 \\
2409 \\
3038 \\
2072 \\
\end{array}$ & $\begin{array}{l}0.90 \\
0.93 \\
0.95 \\
1.00 \\
0.64 \\
0.69 \\
0.99 \\
1.05 \\
0.77 \\
1.00 \\
1.34 \\
0.86 \\
\end{array}$ & $\begin{array}{c}0.50^{\mathrm{b}} / \sim 1.03^{\mathrm{c}} \\
0.49^{\mathrm{b}} \\
\sim 0.82^{\mathrm{c}} \\
\sim 0.94^{\mathrm{c}} \\
\sim 0.64^{\mathrm{c}} \\
0.54^{\mathrm{b}} \\
0.53^{\mathrm{b}} \\
- \\
- \\
0.50^{\mathrm{b}} \\
0.42^{\mathrm{b}} \\
-\end{array}$ & $\begin{array}{l}1.20 \\
1.20 \\
1.10 \\
1.17 \\
1.30 \\
0.80 \\
1.42 \\
1.49 \\
0.90 \\
1.46 \\
1.52 \\
1.20 \\
-\end{array}$ & $\begin{array}{c}8, \\
52,55\end{array}$ \\
\hline $\mathrm{TiC}$ & 600 & $\begin{array}{l}\mathrm{CO}_{2}, 875^{\circ} \mathrm{C}-8 \mathrm{~h} \\
\mathrm{CO}_{2}, 925^{\circ} \mathrm{C}-2 \mathrm{~h} \\
\mathrm{CO}_{2}, 970^{\circ} \mathrm{C}-2 \mathrm{~h} \\
\mathrm{CO}_{2}, 990^{\circ} \mathrm{C}-2 \mathrm{~h}\end{array}$ & $\begin{array}{l}2643 \\
2344 \\
3360 \\
3300 \\
\end{array}$ & $\begin{array}{l}1.05 \\
0.96 \\
1.30 \\
1.36\end{array}$ & $\begin{array}{l}0.46^{\mathrm{b}} \\
0.48^{\mathrm{b}} \\
0.36^{\mathrm{b}} \\
0.32^{\mathrm{b}}\end{array}$ & $\begin{array}{l}1.49 \\
1.35 \\
1.52 \\
1.80 \\
\end{array}$ & 52 \\
\hline $\mathrm{ZrC}$ & 800 & $\begin{array}{c}\mathrm{KOH} / \mathrm{CDC} 4 / 1 \\
\text { (wt./wt.), } 600^{\circ} \mathrm{C}-1 \mathrm{~h} \\
\mathrm{KOH} / \mathrm{CDC} 4 / 1 \\
\text { (wt./wt.), } 700^{\circ} \mathrm{C}-1 \mathrm{~h} \\
\mathrm{KOH} / \mathrm{CDC} 4 / 1 \\
\text { (wt./wt.), } 800^{\circ} \mathrm{C}-1 \mathrm{~h} \\
\mathrm{KOH} / \mathrm{CDC} 4 / 1 \\
\text { (wt./wt.), } 900^{\circ} \mathrm{C}-1 \mathrm{~h}\end{array}$ & $\begin{array}{c}191 \\
2640 \\
2460 \\
2770\end{array}$ & $\begin{array}{l}0.98 \\
1.36 \\
1.23 \\
1.47\end{array}$ & $\begin{array}{l}0.82^{\mathrm{d}} \\
1.08^{\mathrm{d}} \\
1.04^{\mathrm{d}} \\
0.98^{\mathrm{d}}\end{array}$ & $\begin{array}{c}8 / 13 \\
13 / 20 \\
6 / 12 / 22 \\
12 / 23\end{array}$ & 54 \\
\hline
\end{tabular}

${ }^{\mathrm{a} D e t e r m i n e d ~ v i a ~ N L D F T ~ a s s u m i n g ~ s l i t-s h a p e d ~ p o r e s . ~}{ }^{\mathrm{bv}}$ olume of pores $<1.5 \mathrm{~nm}$ determined via NLDFT. ${ }^{\mathrm{cV}}$ olume of pores $<2 \mathrm{~nm}$ determined via NLDFT. ${ }^{\mathrm{d}}$ Determined via t-plot. 

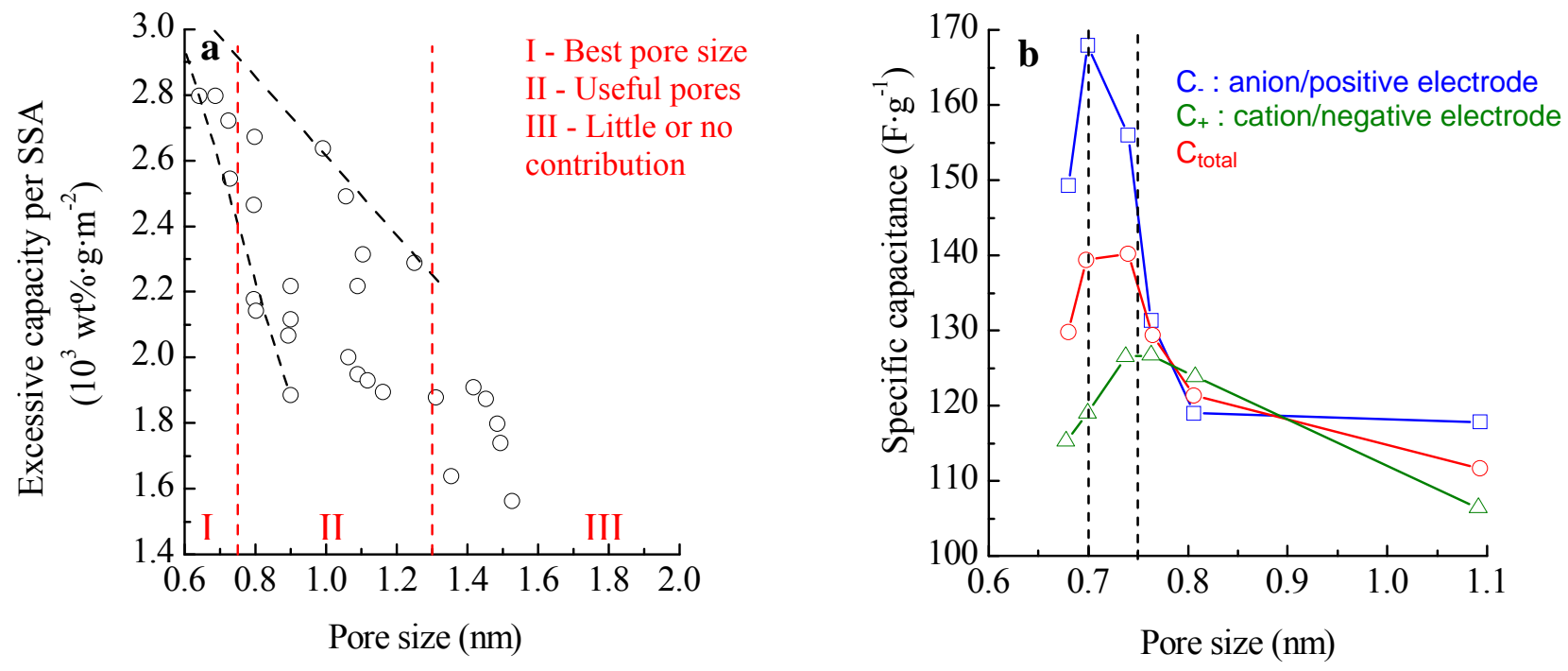

Figure 1. Dependence of (a) excess hydrogen storage capacity on surface area, ${ }^{4}$ and dependence of (b) capacitance on the pore $\operatorname{size}^{9}$ of porous carbon materials. 
a

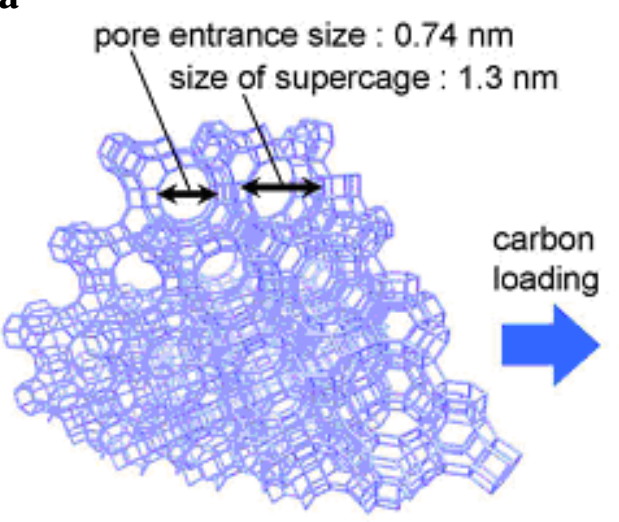

zeolite $Y$

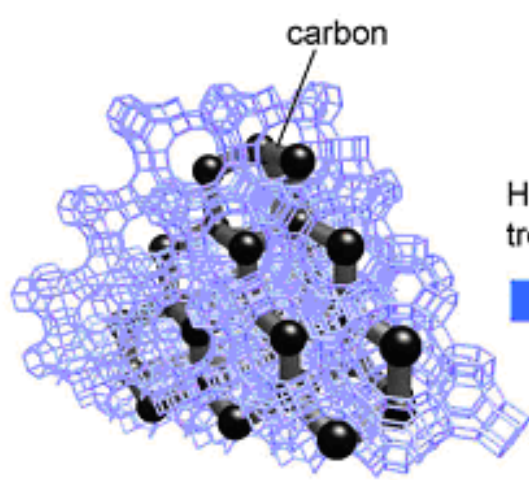

zeolite/carbon composite

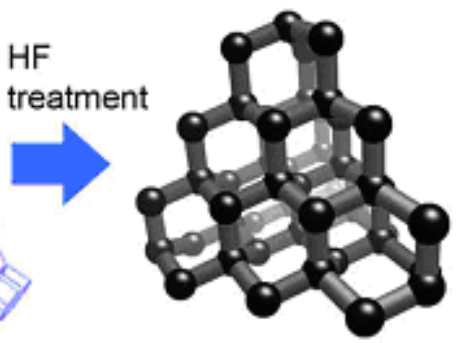

zeolite templated carbon

b

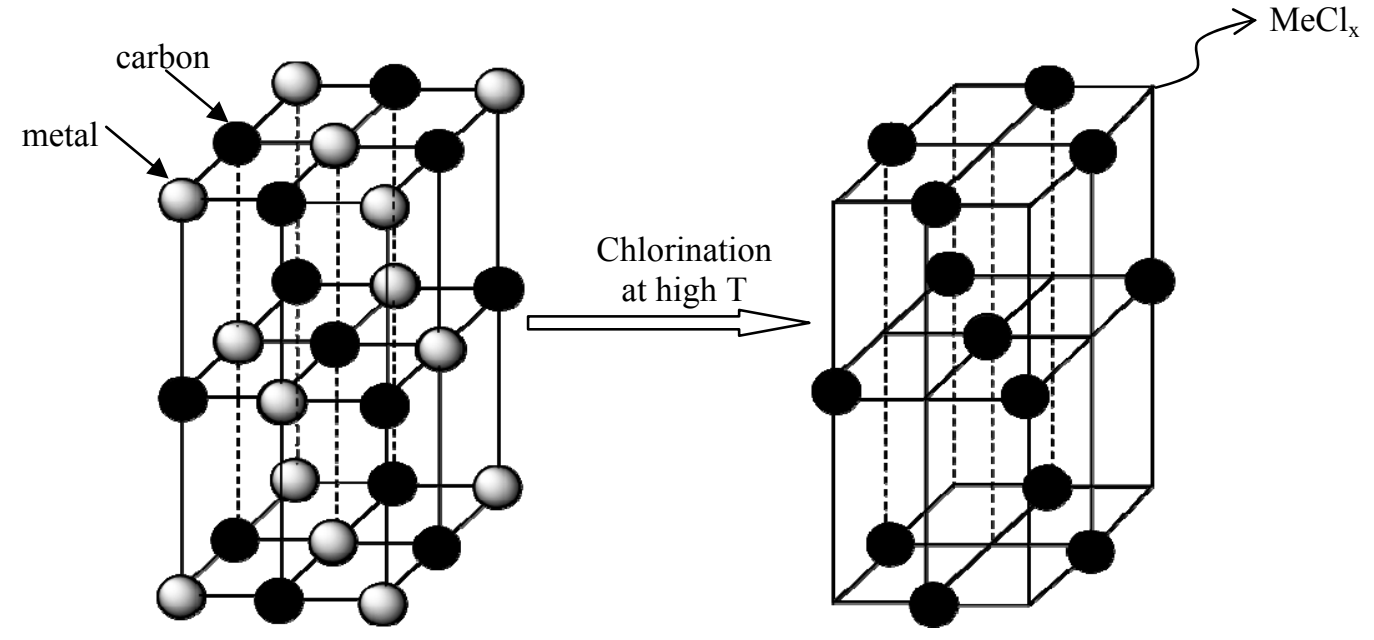

Figure 2. Schematic illustration of (a) the carbon nanocasting technique using zeolite Y as template ${ }^{11}$ and (b) the selective high-temperature chlorination of a metal carbide lattice with a fec structure (such as $\mathrm{TiC}$ and $\mathrm{ZrC}$ ). 


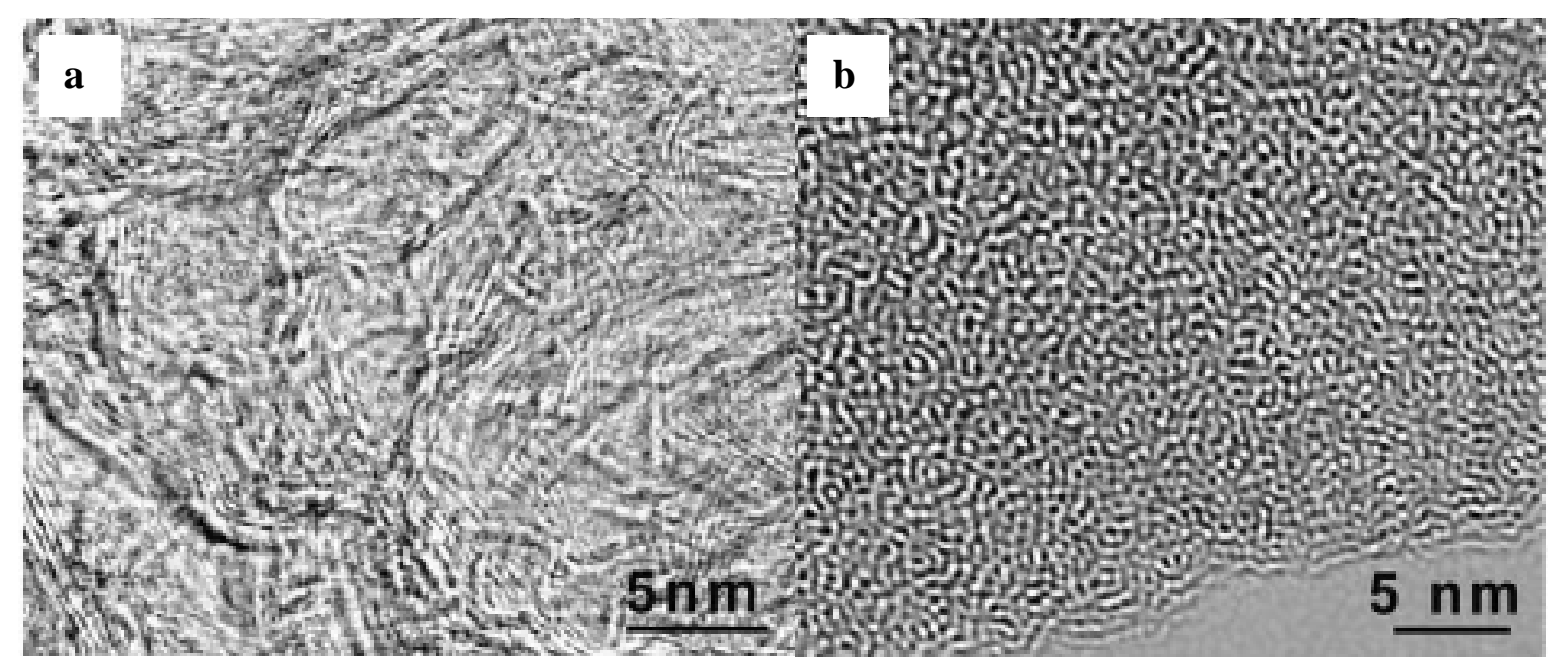

Figure 3. TEM images of $\mathrm{ZrC}-\mathrm{CDC}$ synthesized at (a) $1200^{\circ} \mathrm{C}$ and (b) $600^{\circ} \mathrm{C} .^{10}$ 


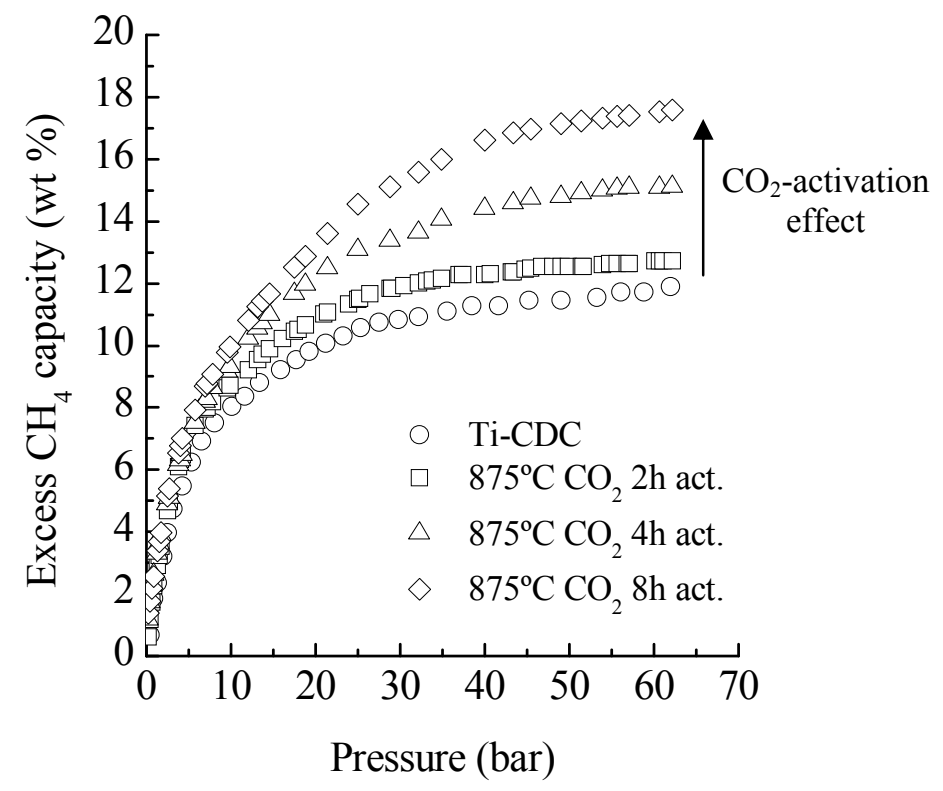

Figure 4. Excess methane adsorption isotherms at $25^{\circ} \mathrm{C}$ over the $0-60$ bar pressure range for a raw Ti-CDC synthesized at $600^{\circ} \mathrm{C}$ and after $\mathrm{CO}_{2}$-activation for $2-8 \mathrm{~h}$ at $875^{\circ} \mathrm{C}^{53}$ 

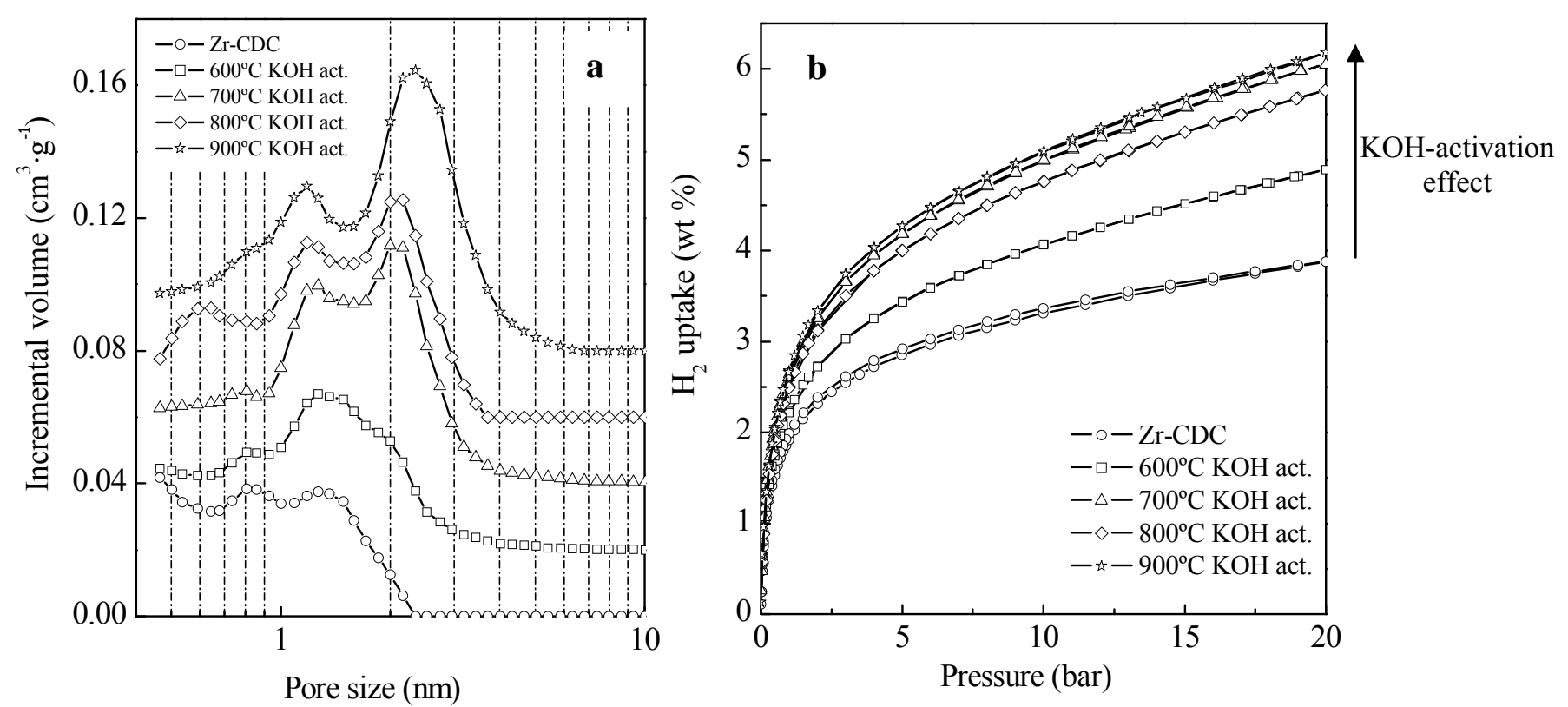

Figure 5. Pore size distribution curves (a) and hydrogen uptake isotherms at $-196^{\circ} \mathrm{C}$ in the pressure range 0 - 20 bar (b) for a raw $\mathrm{Zr}-\mathrm{CDC}$ synthesized at $800^{\circ} \mathrm{C}$ and its $\mathrm{KOH}-$ activated carbons. $^{54}$ 